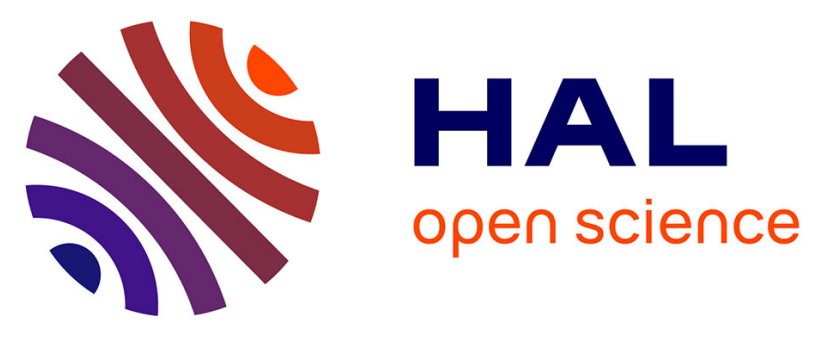

\title{
Flexibility Assessment of Heat Exchanger Networks: From a Thorough Data Extraction to Robustness Evaluation
}

Lucille Payet, Raphaële Théry Hétreux, Gilles Hetreux, Florent Bourgeois, Pascal Floquet

\section{To cite this version:}

Lucille Payet, Raphaële Théry Hétreux, Gilles Hetreux, Florent Bourgeois, Pascal Floquet. Flexibility Assessment of Heat Exchanger Networks: From a Thorough Data Extraction to Robustness Evaluation. Chemical Engineering Research and Design, 2018, 131, pp.571-583. 10.1016/j.cherd.2017.11.036 . hal-01886929

\section{HAL Id: hal-01886929 https://hal.science/hal-01886929}

Submitted on 3 Oct 2018

HAL is a multi-disciplinary open access archive for the deposit and dissemination of scientific research documents, whether they are published or not. The documents may come from teaching and research institutions in France or abroad, or from public or private research centers.
L'archive ouverte pluridisciplinaire HAL, est destinée au dépôt et à la diffusion de documents scientifiques de niveau recherche, publiés ou non, émanant des établissements d'enseignement et de recherche français ou étrangers, des laboratoires publics ou privés. 


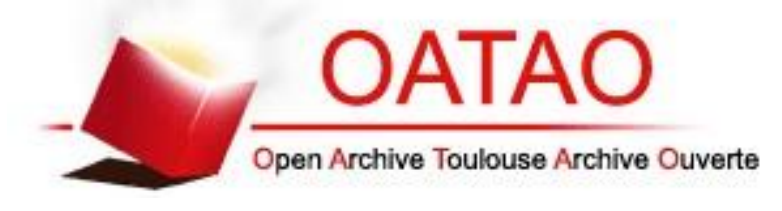

\section{Open Archive Toulouse Archive Ouverte}

OATAO is an open access repository that collects the work of Toulouse researchers and makes it freely available over the web where possible

This is an author's version published in: http://oatao.univ-toulouse.fr/20898

Official URL: https://doi.org/10.1016/j.cherd.2017.11.036

\section{To cite this version:}

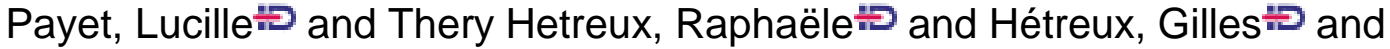
Bourgeois, Florent"כ and Floquet, Pascal Exchanger Networks: From a Thorough Data Extraction to Robustness Evaluation. (2018) Chemical Engineering Research and Design, 131. 571583. ISSN 0263-8762

Any correspondence concerning this service should be sent to the repository administrator: tech-oatao@listes-diff.inp-toulouse.fr 


\title{
Flexibility Assessment of Heat Exchanger Networks: From a Thorough Data Extraction to Robustness Evaluation
}

\author{
Lucille Payet*, Raphaële Thery Hétreux, Gilles Hétreux, Florent Bourgeois, \\ Pascal Floquet \\ Laboratoire de Génie Chimique, Université de Toulouse, CNRS, INPT, UPS, Toulouse, France
}

\begin{abstract}
A B S T R A C T
Due to process variabilities and operational modifications, operating parameters of Heat Exchanger Network (HEN) may alter its output temperatures. Nevertheless, the impact of these disturbances depends largely on the topology of the HEN. As a consequence, it can be relevant to evaluate the flexibility of a HEN after its synthesis. Flexibility of a HEN refers to the ability of a system to operate at a finite number of set points. In this framework, the implementation of this property is broken down into several aspects. In this contribution, the first level of flexibility concerning the robustness (ability of the system to absorb disturbances without changing utility flowrates) is addressed and compared to other contribution, this criterion is not formulated as a generic one but as a criterion that strongly depends on the studied process. As a consequence, to evaluate its value, the first step is to perform an enhanced data collection by identifying the most frequent disturbances and by pointing out the critical streams i.e. the streams whose output temperature absolutely needs to be kept into a strict interval; then, given this information, a robustness criterion can be formulated for a given HEN. In this paper, a methodology relying on several models is developed to address this issue: a Mass Equilibrium Summation enthalpy non-linear model (MESH) dedicated to the enhanced data collection, a Mixed Integer Linear Programming (MILP) model used for the HEN synthesis and finally a linear model developed for the modeling of the HEN response to disturbances. This methodology is first illustrated through a basic academic example and finally applied to an industrial case study.
\end{abstract}

\section{Introduction}

The energy issue is paramount to improving the performances of industrial processes as it impacts their economic profitability and environmental footprint. One of the most effective strategies to improve the energy efficiency of industrial sites is to maximize heat recovery by Process Integration (PI), as still pointed out recently by Pereira et al. (2017). Indeed, PI is an essential concept which consists in coupling the hot and cold streams internal to the process rather than consuming external utilities. The PI methodology is based on the Pinch Analysis
(PA) (Linnhoff and Hindmarsh, 1983) and leads to the Heat Exchanger Network (HEN) as a final solution to achieve a significant reduction of energy consumption.

By design, a HEN leads to a stronger integration of hot and cold streams. There is a substantial literature on HEN design methods, as reflected in Furman and Sahinidis (2002), which lists and analyses as many as 461 articles from the late 40 s to 2000 . This study highlights different methodologies that were carried out. The approaches concern algorithmic methods, methods based on heuristics or mathematical programming techniques. According to the authors, in recent 


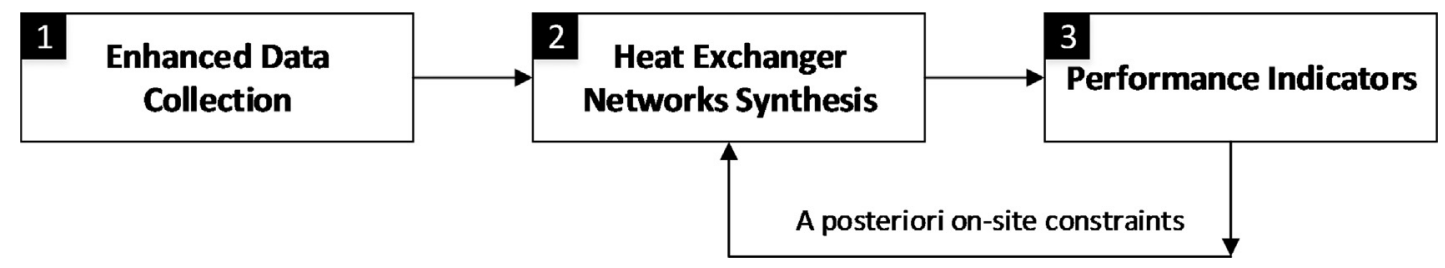

Fig. 1 - RREFlex methodology.

years, the latter predominates and the need for more robust formulations and more efficient global optimization algorithms is all the more crucial. In this framework, Escobar and Trierweiler (2013) displays a case study comparison between several mathematical models: Mixed Integer Non Linear Programming (MINLP), Non Linear Programming (NLP), Mixed Integer Linear Programming (MILP) and Linear Programming (LP) to test their efficiency on a few examples. Simultaneous and sequential methods are also compared in this study. The authors concludes that whereas sequential methods, which solve the problem step by step, are easier to solve, simultaneous methods, which solve the problem in one step, provide better solutions. Another observation is that most of the proposed methodologies aim to derive solutions that minimize the site's energy consumption by achieving the best compromise between the capital expenditures (CAPEX) and the operational cost (OPEX) (Gundersen and Naess, 1990; Barbaro and Bagajewicz, 2005; Björk and Westerlund, 2002; Escobar and Trierweiler, 2013; Isafiade and Fraser, 2008; Mehta et al., 2001; Mikkelsen and Qvale, 2001; Morar and Agachi, 2010; Yee and Grossmann, 1990). However, these solutions do not always give rise to a concrete implementation on industrial sites. As suggested in Sreepathi and Rangaiah (2014), a single optimal solution is generally not sufficient for the industrial feasibility of the HEN due to unforeseen on-site constraints. The challenge with designing viable HEN is that it is simply not possible to identify and formulate all constraints out of hand. Sreepathi and Rangaiah (2014) concluded that it would be better to provide several optimal solutions so that experienced engineers can select the most practical HEN. To address this issue, this paper presents a computational framework developed as part of the RREFlex project (Software for the Robust Synthesis of Flexible HEN). This tool proposes an original approach, which consists in an iterative process relying on 3 major points as shown in Fig. 1:

- The analysis of the process historical data to identify precisely the on-site constraints.

- The proposal and evaluation of several configurations of HEN achieved by an optimization approach based on Mixed Integer Linear Programming (MILP).

- The a posteriori evaluation of the performances of these configurations: performance indicators are relative to on-site considerations such as topology of the HEN or its flexibility in addition to more traditional indicators like energy consumption and global costs. The analysis of these solutions by the engineer leads to the formulation of new constraints and the synthesis of new HEN. The procedure is run until finally obtaining configurations which fulfill all the industrial constraints correctly.

Thus, the methodology proposed in this work consists in providing the site engineer with several HEN solutions and letting him post-evaluate the performance of each one using key performance indicators (KPIs) based on economical, topological, practical and operational considerations. The method therefore assigns the end-user a pivotal deciding role, and new improved HEN solutions are designed iteratively as the end-user adds in additional on-site constraints. With such a scheme, one HEN solution provides the basis for the next one, and the design process stops when KPIs can no longer be improved and on-site constraints have all been accounted for.

As mentioned, a multi-criteria evaluation of each proposal is carried out in the RREFlex tool. Among these KPIs, flexibility appears as one of the most crucial ones. Many definitions of HEN flexibility can be found in the literature for continuous processes (Escobar et al.,
2013; Verheyen and Zhang, 2006; Chen and Hung, 2004). Nevertheless, a common definition of flexibility is the ability of a system to operate for a finite number of operating points. Moreover, it is often referred as resilience index (Saboo et al., 1985) or controllability for dynamic and steady-state regime of processes (Swaney and Grossmann, 1985; Pintarič and Kravanja, 2004; Masoud et al., 2016). In Escobar et al. (2013), a two-stage methodology is reported for designing of a flexible and controllable HEN. Their first stage consists in the design of an optimal HEN that minimizes the CAPEX and OPEX, using the SYNHEAT non-linear model from Yee et al. (1990). Their second stage deals specifically with the flexibility issue by minimizing the sensitivity of the HEN to disturbances. The methodologies to establish directly resilient HEN for grass-root cases was thus well studied. For the post-evaluation of the flexibility of HEN in retrofit cases, this notion has to take into account batch processes but still including the notion of resilience. Moreover, the definition of HEN resilience as the ability to cope with inlet and target temperature changes in Saboo et al. (1985) required to be divided into two notions. In all cases, such a flexibility analysis clearly requires accounting for all the relevant process uncertainties. Whereas, the design of robust HEN for green or new projects can be considered mature as new facilities offer the maximum design flexibility for heat integration, this is not the case however for brown or existing projects. As highlighted by Smith et al. (2010), retrofitting a flexible HEN to an operating plant remains a complex and critical problem.

In our methodology, the general property of flexibility has been subdivided into 4 layers:

- Robustness (or inherent resilience): the intrinsic ability for the HEN to cope with inlet temperature small changes with no topological changes.

- Potential resilience: the ability to achieve the resilience by acting on the utility flow rates or/and introducing by-passes solutions in order to make the HEN able to absorb the disturbances.

- Adaptability: the ability of a system to operate at a finite set of operating points.

- Intermittency management: the ability to overcome temporal mismatches between hot and cold heat sources (summer/winter operation, batch processes, etc...) by means of storage tanks that must be characterized.

In view of the complexity of the subject, only robustness property (first layer of the HEN flexibility) is addressed in this paper and compared to existing methods, robustness criterion is defined as a specific one that strongly depends on the history of the considered process.

To enable RREFlex software to assess the robustness of the HEN for a given process, a three-step methodology has been developed starting from an enhanced data collection for the calculation of enriched data for pinch key values (mean values and standard deviation of temperatures) and ending with the definition of a robustness criterion. In this framework, disturbances on inlet streams have to be characterized and tolerance intervals on outlet values have to be established by engineers. In order to obtain the required information, a generic data extraction methodology based on process history is developed. For that purpose, physical data (as stream flowrate, heat capacity and inlet/outlet temperatures) are assumed to follow a normal distribution. This representation is widely used in data extraction and validation methodology in chemical processes (Romagnoli and Sanchez, 1999). The data are then modelled by its mean value and standard deviation which would be a thinner representation of the variations than 


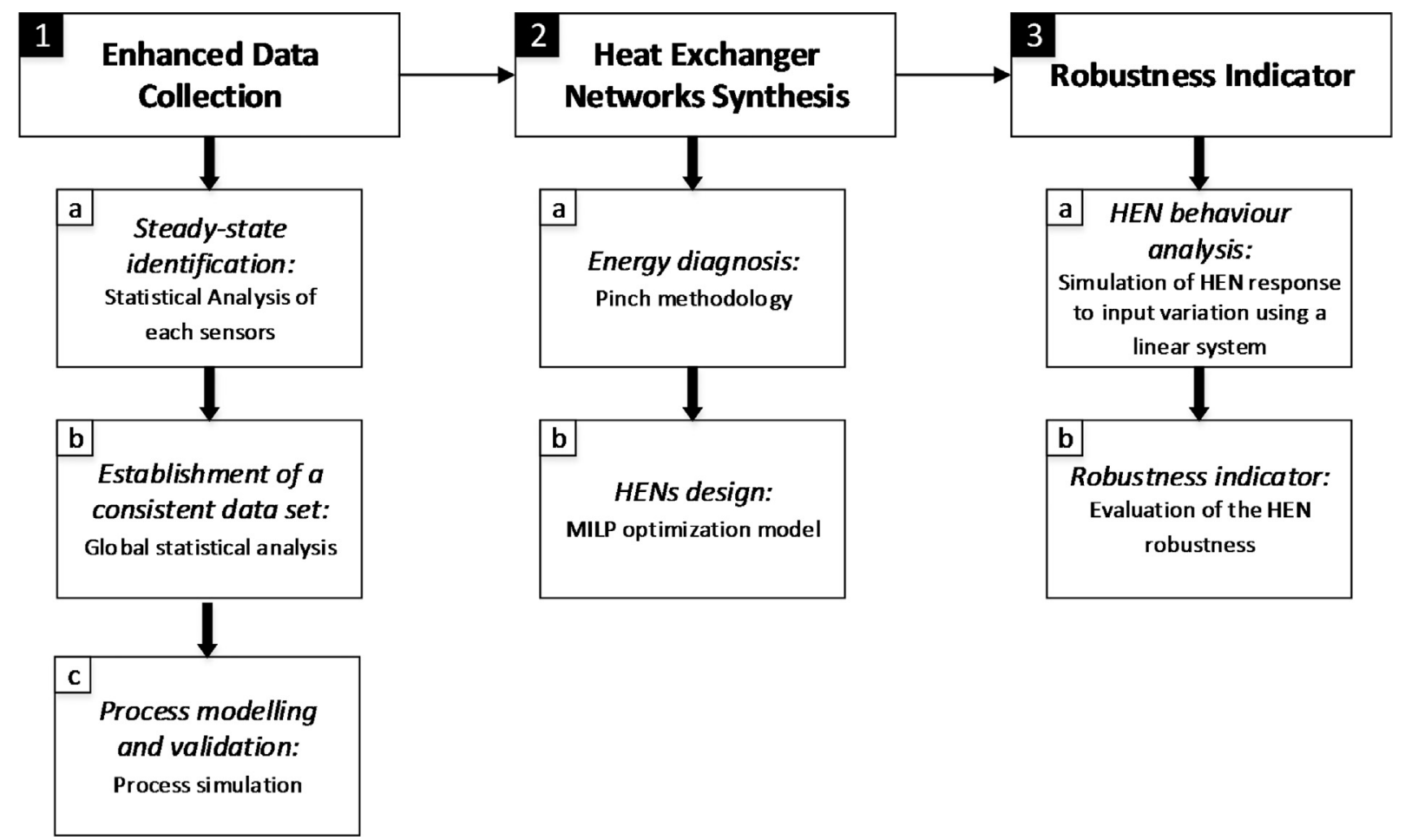

Fig. 2 - Global multi-model three-step methodology used to derive a HEN robustness indicator.

a mere range. The exploitation of historical data would then exclude less possible HEN solution but requires a specific methodology. Several methodologies described in the literature address the data extraction issue. Venkatasubramanian et al. (2003) established a classification of diagnostic algorithms. For process history based quantitative statistical study, both Principal Component Analysis (PCA)/Partial Least Squares (PLS) (work of Kresta et al., 1991 and Kourti and MacGregor, 1995 for instance) and Statistical Pattern Classifiers (see Fukunaga, 1990) can be used. According to Venkatasubramanian et al. (2003), it is important to design hybrid systems to assess large-scale industrial situations and overcome the drawbacks of single-method based diagnosis. To develop an adaptable and accurate approach, we have developed a hybrid methodology using a statistical analysis coupled with a process modelling software.

The remainder of this paper is organized as follows. The outline of the methodology for evaluating the robustness indicator is described in Section 2. The rest of the paper details each step as follow. Section 3 discusses the statistical analysis module called EDiFy and the validation model with ProSimPlus ${ }^{\odot}$. Then, Section 4 describes the optimisation model used for the synthesis of several HEN configurations. The HENSim module dedicated to the simulation of HEN behaviour with respect to the identified input variations is presented in Section 5. Finally in Section 6 , the methodology is applied on a real industrial case study and results are discussed.

\section{Outline of the proposed methodology for robustness analysis of HEN}

Fig. 2 proposes an overview of the global methodology that was implemented for the robustness analysis. Several kinds of models are required to build and assess the robustness of a HEN. Starting from process historical data, the procedure is structured around three major steps:

- Step 1: Enhanced data collection for the flexibility analysis of HEN (method EDiFy)

The raw data (temperature, pressure, flowrate. . .) measured by several sensors available in the plant are analysed in order to determine one or several nominal set point(s) and obtain a consistent data set representative of each set point. A statistical representation of each representative data is then proposed to enable the computation of HEN alternatives.

- Step 2: The computation of several Heat Exchanger Network alternatives

Given the mean values of input/output temperatures and FCp for each hot and cold stream, several alternative of HEN are computed using a Mixed Integer Linear Programming approach (MILP).

- Step 3: The simulation of HEN behaviour under steady state conditions

The robustness of each configuration according to the input variations identified in step 1 is then assessed using HENSim model (Heat Exchanger Network Simulation). The robustness property evaluates the capacity of the HEN to maintain the output temperatures of critical streams into predefined bounded intervals. In this framework, a critical stream is a sensitive process stream with strict and narrow tolerance limits in terms of temperature, such as a reactor input stream for instance. These tolerance limits fix the bounded interval and are either calculated from historical data or specified by process engineers. Exceeding the tolerance limits of a critical stream could lead to hazardous consequences in terms of safety or process performances. According to this point of view, either the tolerance limits are respected for all the critical streams studied and the network is considered unilaterally robust, or these limits are not satisfied for few streams and the robustness of the network is quantified via an indicator comprised in the interval $[0,1]$.

In the following sections, the methodology will be extensively detailed. To illustrate the steps of the global methodology, a Simple Process example is used. In Fig. 3, a theoretical production process of desired products $\mathrm{C}$ and $\mathrm{E}$ from 


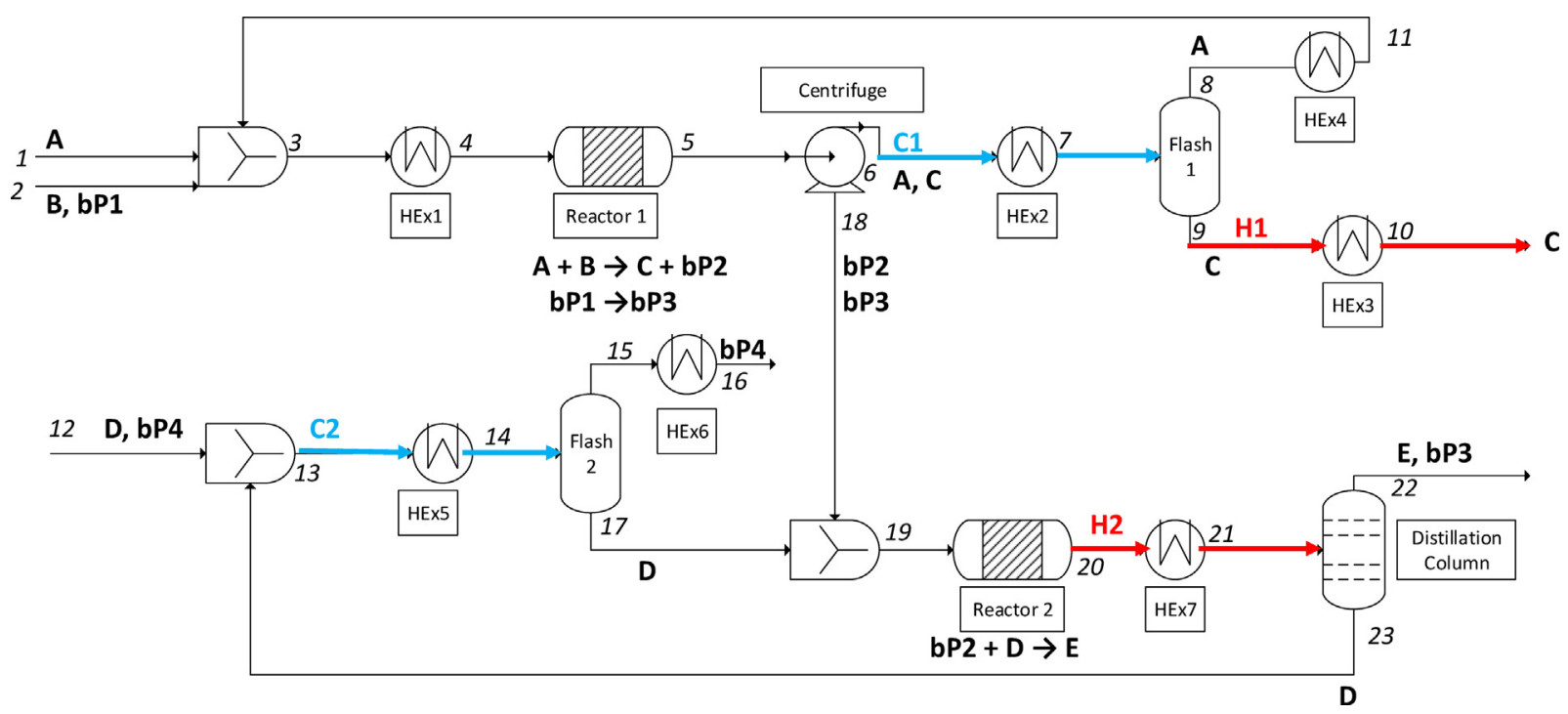

Fig. 3 - Simple Process example (SP).

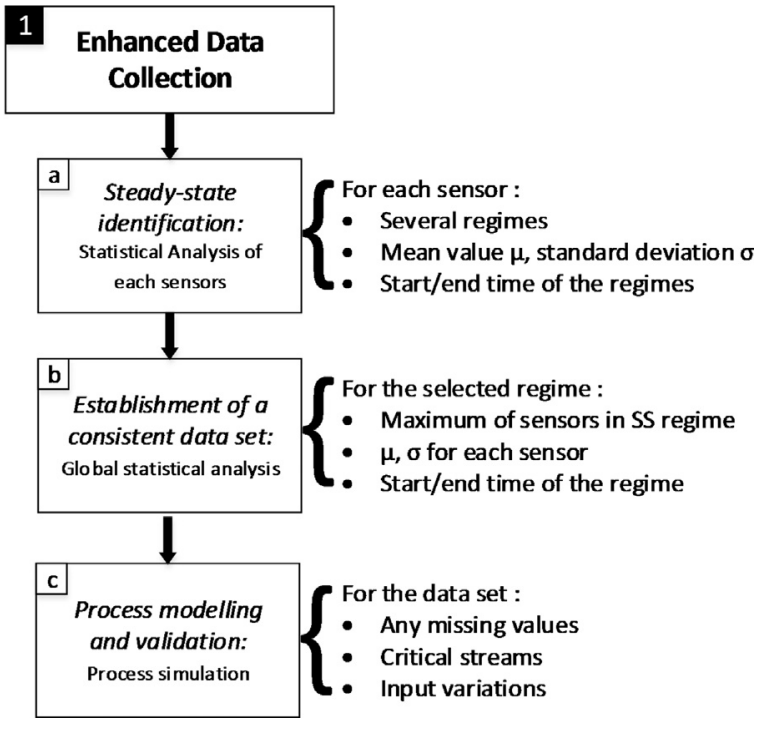

Fig. 4 - EDiFy methodology flowchart.

A, B and D with several by-products is displayed. This Simple Process (SP) is composed of 7 heat exchangers, 2 reactors and 4 separation units. In the nominal process, all the heat exchangers are coupled with hot and cold utilities (no heat integration of the process). In the scenario chosen for this study, exchangers Hex2, Hex3, Hex 5 and Hex7 will be reconsidered. The heat integration of cold streams C1 and C2 and of hot streams H1 and $\mathrm{H} 2$ will then be studied. Assuming that this process is well-instrumented, the first step of the methodology consists in determining the operating point and variations of the site as well as its critical streams (step 1). Then, several alternatives of Heat Exchanger Networks are proposed (step 2). Finally all these alternatives are compared to each other in terms of robustness (step 3).

\section{Step 1: method EDiFy (Enhanced Data Collection for Flexibility Analysis)}

The module EDiFy consists in a thorough analysis of industrial process data relying on the analysis of historical data from the considered site. The methodology illustrated in Fig. 4 is composed of three sub-steps.
The first one aims at identifying all the steady-state operating points of every sensors of the site. It consists in the analysis of the raw data recorded from the industrial site. It includes a statistical analysis developed specifically to enable the definition of one or more accurate steady-state measurements. To this end, records from all available sensors are analysed using a dedicated application based on sliding windows. For every steady-state (SS) regime isolated by the analysis, the module yields the statistical distribution (Gaussian) of the input and output temperatures, pressure and flowrates of all process streams.

The second step consists in the establishment of a consistent data set (for sub-step 1c). A global statistical analysis is carried out to select the period with the greatest number of sensors in SS.

Finally, to validate the data required in the HEN synthesis and robustness analysis, the process steady-state regime previously identified is used as input data in a simulation model of the process. This model is based upon Mass Equilibrium Summation enthalpy (MESH) equations (in ProSimPlus ${ }^{\odot}$ simulation software). Missing values are identified according to heat and mass balances. The critical streams and input variations are also determined.

This hybrid method coupling statistical analysis and process modelling enables the definition of the mean value and the standard deviation of flowrate and inlet/outlet temperatures of each stream of the process.

\subsection{Statistical analysis for each sensors and steady-state regimes identification}

First, the SS operating periods for all available sensors needs to be identified. Assuming a normal distribution of measure, the analysis relies on a basic sliding windows analysis through which historical data are processed in order to separate and characterise distinct SS operating regimes from the recording of every individual sensors. The size of the sliding windows is matched to the coefficient of variation (CV) of the sensor's signal and precision, in order to identify the time windows over which each sensor's signal is operating under steady-state (Fig. 5).

First, large sliding windows (101 points) are used to separate changes in steady-state regimes, then sliding windows 

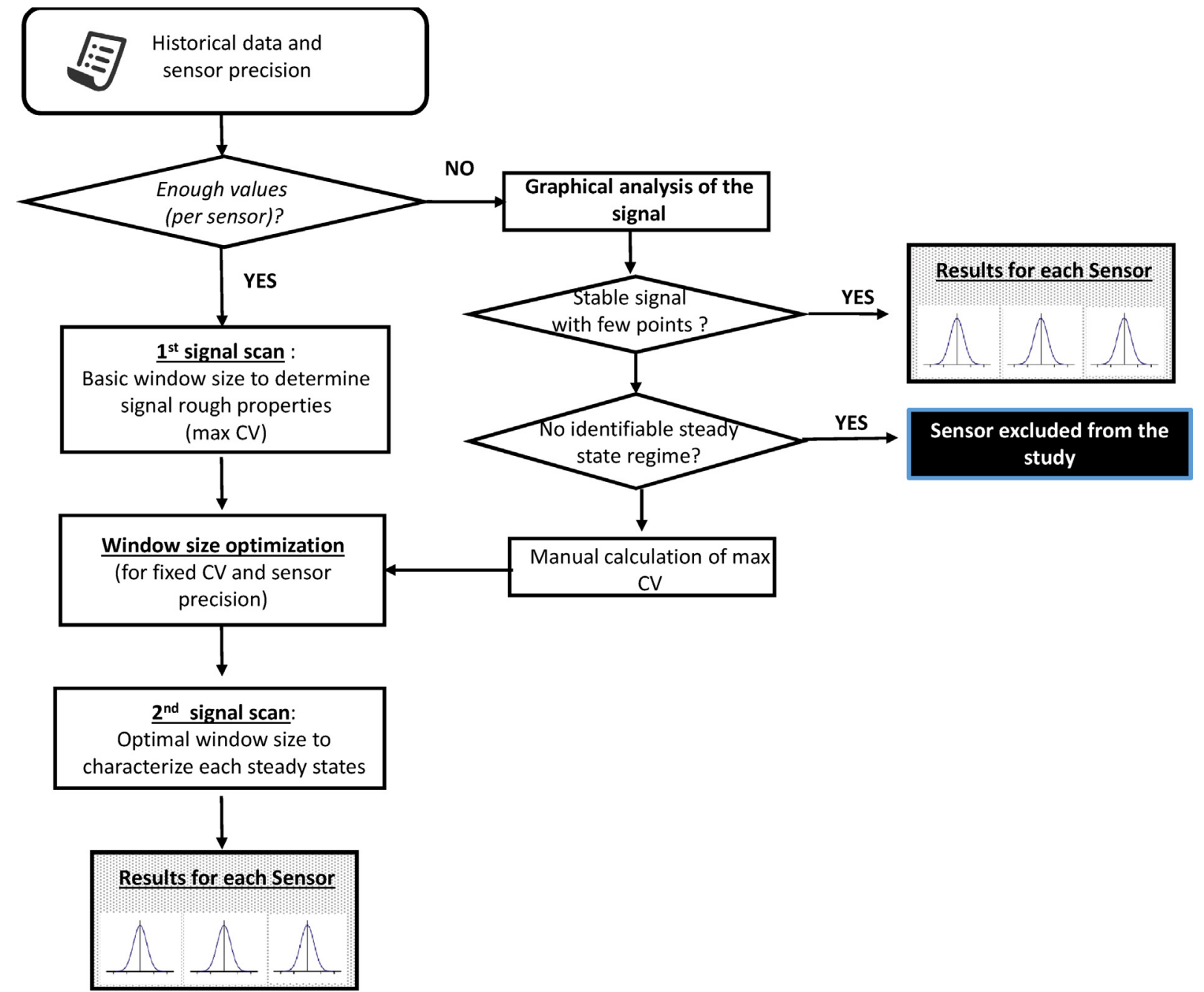

Fig. 5 - Sub-step 1a: statistical analysis of each sensors and steady-state identification.

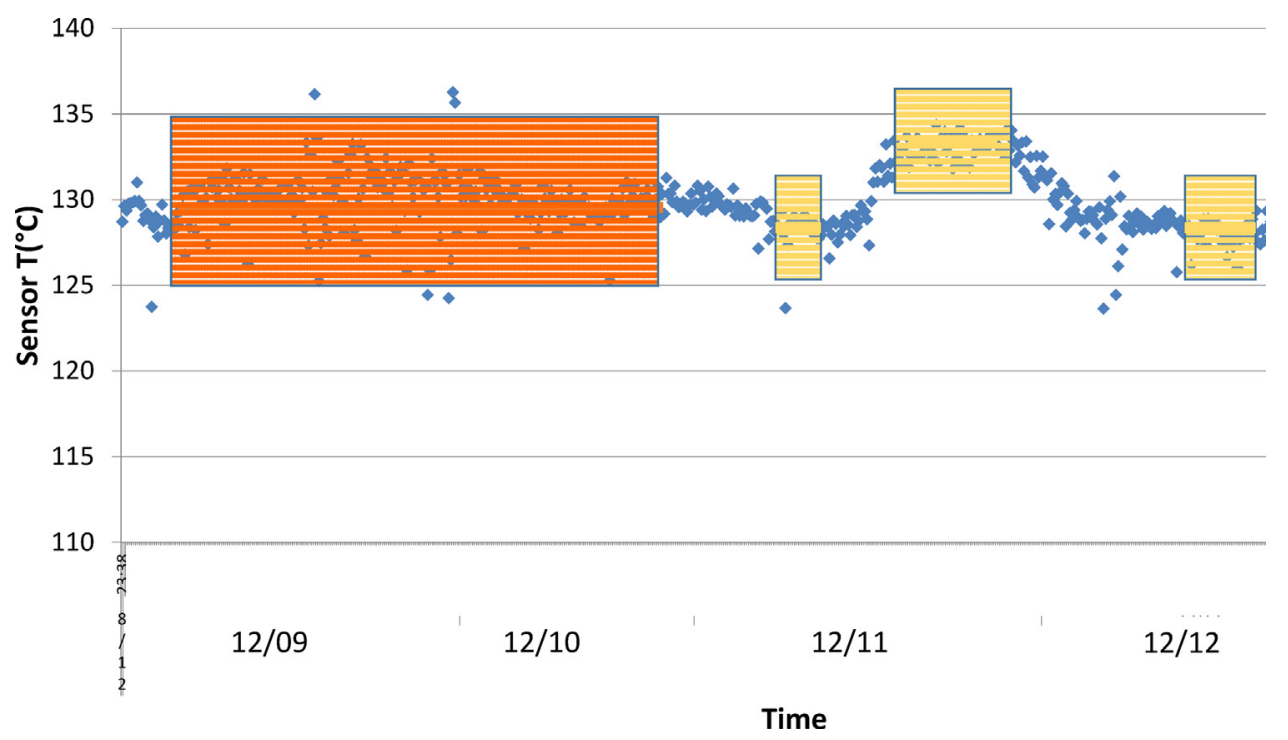

Fig. 6 - Temperature Sensor SS identification.

size is progressively decreased in order to isolate the broadest range of values over which the sensor signal is at steady-state. An accurate data analysis over the steady-state range finally leads to the statistical distribution of the raw signal. Of course, the strength and applicability of the method strongly depends on the amount of available data. In case of missing data or inconsistent signal, the data from the sensor is discarded from the analysis.

Application on the Simple Process example

Fig. 6 displays the signal measured by a sensor and exhibits several SS regimes. The normal distribution of the first steadystate regime is also illustrated in Fig. 7. The mean value, 


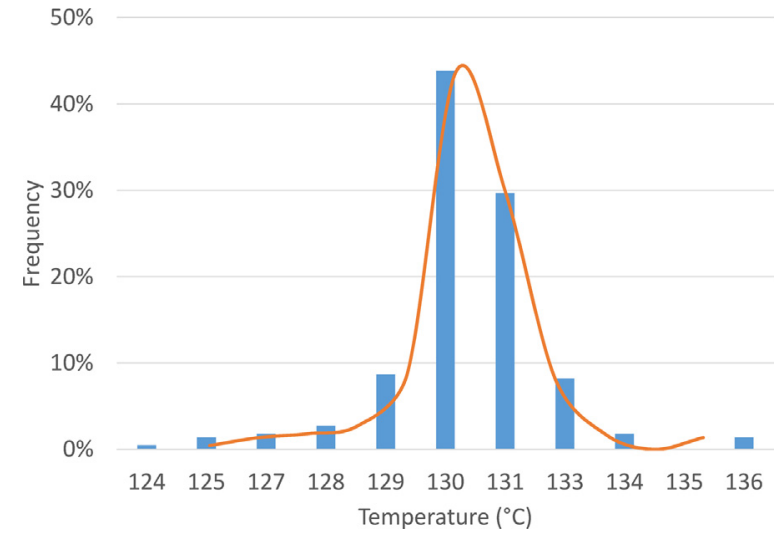

Fig. 7 - Steady-state regime 1 of representative sensor.

standard deviation and coefficient of variation (standard deviation over mean ratio) are calculated for each SS as well as the start and end time of each regime.

\subsection{Establishment of a consistent data set as input of a process simulation software}

Given the steady-state periods for each individual sensor, the global representative steady-state period can now be found. It corresponds to the periods displaying the greatest number of sensors operating under steady-state conditions. If necessary, sensors can be ranked according to their topological area in order to take time lag between areas into account. The data for each SS regime are fed to a process simulation software, namely ProSimPlus ${ }^{\odot}$, in order to validate the consistency of data for heat and mass balances. The main steps of this step are displayed in Fig. 8.

\section{Application on the Simple Process example}

For the Simple Process, a total of 40 sensors are treated. Then the number SS is quantified over the whole period of the study. In Fig. 9, a representative data set for the process modelling over 4 days with over 30 sensors in SS can be detected.

\subsection{Process modelling and validation}

The resulting data sets are then used to obtain an accurate model of the process (Fig. 10). In this study, ProSimPlus ${ }^{\odot}$ software has been used. Among all of the collected data, some are used as input values to configure the model whereas others are used to check the model consistency regarding heat and mass balances. In case of conflict between simulated and measured values, the engineer is advised and asked for advice. Another model validation relies on a comparison between the global utilities bill and the energy consumption deduced from the model. Finally, missing data are then extracted to perform the energy diagnosis and HEN synthesis.

\section{Application on the Simple Process example}

Up to this point, all the process values can be defined. Fig. 10 shows for instance all the temperatures of the system, either they were deduced through statistical analysis (in brown) or by the process simulation model (in green). If the data are extracted from EDIFy, extra information is available such as standard deviation, CV, start and end point of the steady-state regime selected. Pressures and flowrates are also calculated but were not displayed on the graph so as to be more understandable.

Table 1 - Simple Process information for energy diagnosis.

\begin{tabular}{llllll} 
Condition & Stream & FCp $(\mathrm{kW} / \mathrm{K})$ & Tin $\left({ }^{\circ} \mathrm{C}\right)$ & Tout $\left({ }^{\circ} \mathrm{C}\right)$ & $\mathrm{Q}(\mathrm{kW})$ \\
\hline Hot & H1 & 2 & 180 & 40 & 280 \\
Hot & H2 & 4 & 150 & 40 & 440 \\
Cold & C1 & 3 & 60 & 180 & 360 \\
Cold & C2 & 2.6 & 30 & 130 & 260 \\
\hline
\end{tabular}

Table 2 - Pinch Analysis of the SP.

\begin{tabular}{lllll}
$\Delta$ Tmin & Tpinch & Quc,min & QuH,min & MER \\
\hline $10^{\circ} \mathrm{C}$ & $145^{\circ} \mathrm{C}$ & $160 \mathrm{~kW}$ & $60 \mathrm{~kW}$ & $220 \mathrm{~kW}$ \\
\hline
\end{tabular}

Table 3 - SP Variations of input temperatures.

\begin{tabular}{llll} 
Variable streams & $\mathrm{T}_{\text {mean }}$ & $\sigma_{\mathrm{T}}$ & $\mathrm{CV}$ \\
\hline $\mathrm{H} 1$ & $180^{\circ} \mathrm{C}$ & $18^{\circ} \mathrm{C}$ & 0.10 \\
$\mathrm{C} 1$ & $60^{\circ} \mathrm{C}$ & $6^{\circ} \mathrm{C}$ & 0.10 \\
\hline
\end{tabular}

Table 4 - SP Critical stream properties.

\begin{tabular}{llcl} 
Critical stream & $\mathrm{T}_{\text {min }}$ & $\mathrm{T}_{\text {mean }}$ & $\mathrm{T}_{\max }$ \\
\hline $\mathrm{C} 2$ & $123.5^{\circ} \mathrm{C}$ & $130^{\circ} \mathrm{C}$ & $136.5^{\circ} \mathrm{C}$ \\
\hline
\end{tabular}

As mentioned in Section 2, the study focuses on the streams C1, C2, H1 and H2. After the model validation through process simulation (not detailed in this paper), the nominal process values concerning the energy analysis can be extracted (see Table 1 ). Assuming a $\Delta$ Tmin equal to $10^{\circ} \mathrm{C}$, the Problem Table Algorithm leads to the Minimal Energy Requirement given in Table 2. In Table 2, $\Delta$ Tmin is the minimum approach temperature, Tpinch is the Pinch temperature of the system for $\Delta \mathrm{Tmin}, \mathrm{Q}_{\mathrm{UC} \text {,min }}$ is the minimum cold utility heat load, $\mathrm{Q}_{\mathrm{UH}, \mathrm{min}}$ is the minimum hot utility heat load and MER is the Minimum Energy Requirements as defined in Linnhoff and Hindmarsh (1983).

EDiFy methodology leads to information concerning the standard deviation observed on key values such as input temperatures of the future HEN. Table 3 displays the data for $\mathrm{H} 1$ and C1 streams.

Moreover, engineers identified the stream C2 as a critical stream. The boundaries are fixed according to the signal with a threshold of $99.7 \%( \pm 3 \sigma)$ of the distribution. The target properties of C2 output temperature are displayed in Table 4.

\section{Step 2 - synthesis of several HEN configurations}

Given the hot and cold streams characteristics established in step 1, several HEN configurations have to be computed. In the RREFlex approach, a simultaneous method based on Mixed Integer Linear Programming (MILP) is selected to guarantee the efficient calculation of several configurations in case of industrial scale problem. CPLEX kernel is used through ILOG IDE software (IBM). The formulation of the MILP model is based on the notion of temperature interval and bipartite flow graph.

As illustrated on Fig. 11, a process stream can be heated up or cooled down by several heat exchangers. A temperature interval of hot (resp. cold) stream is defined by input/output temperatures of a given heat exchange on the considered stream. For instance, hot stream $\mathrm{H} 1$ exhibits two exchanges on Fig. 11. Then, it is split into two temperature intervals: 


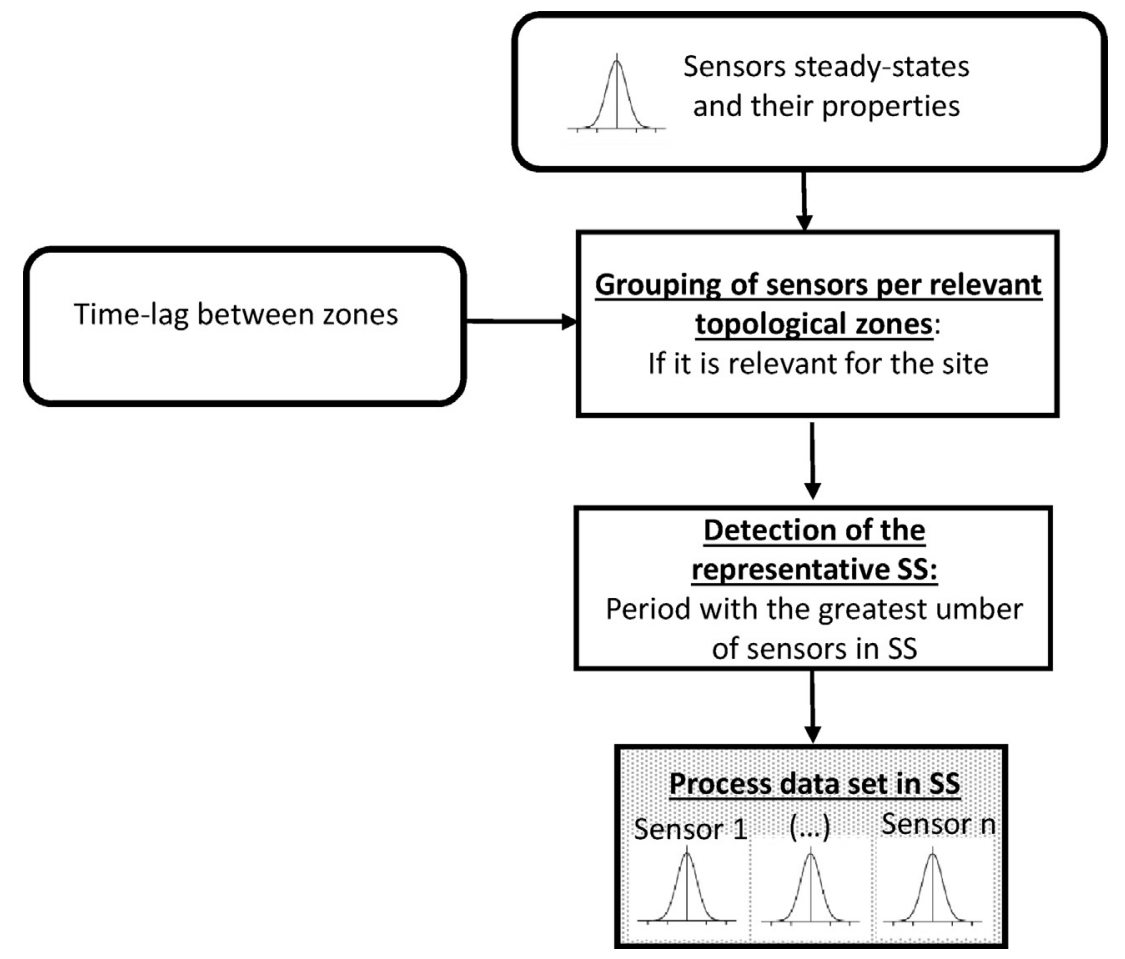

Fig. 8 - Sub-step 1b: global statistical analysis.

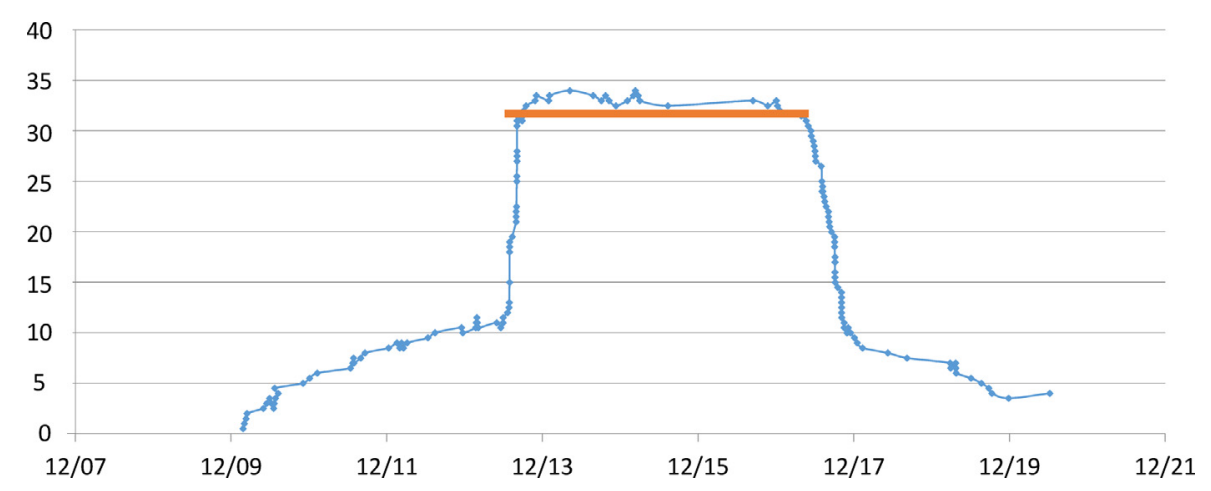

Fig. 9 - Process representative period in SS selection.

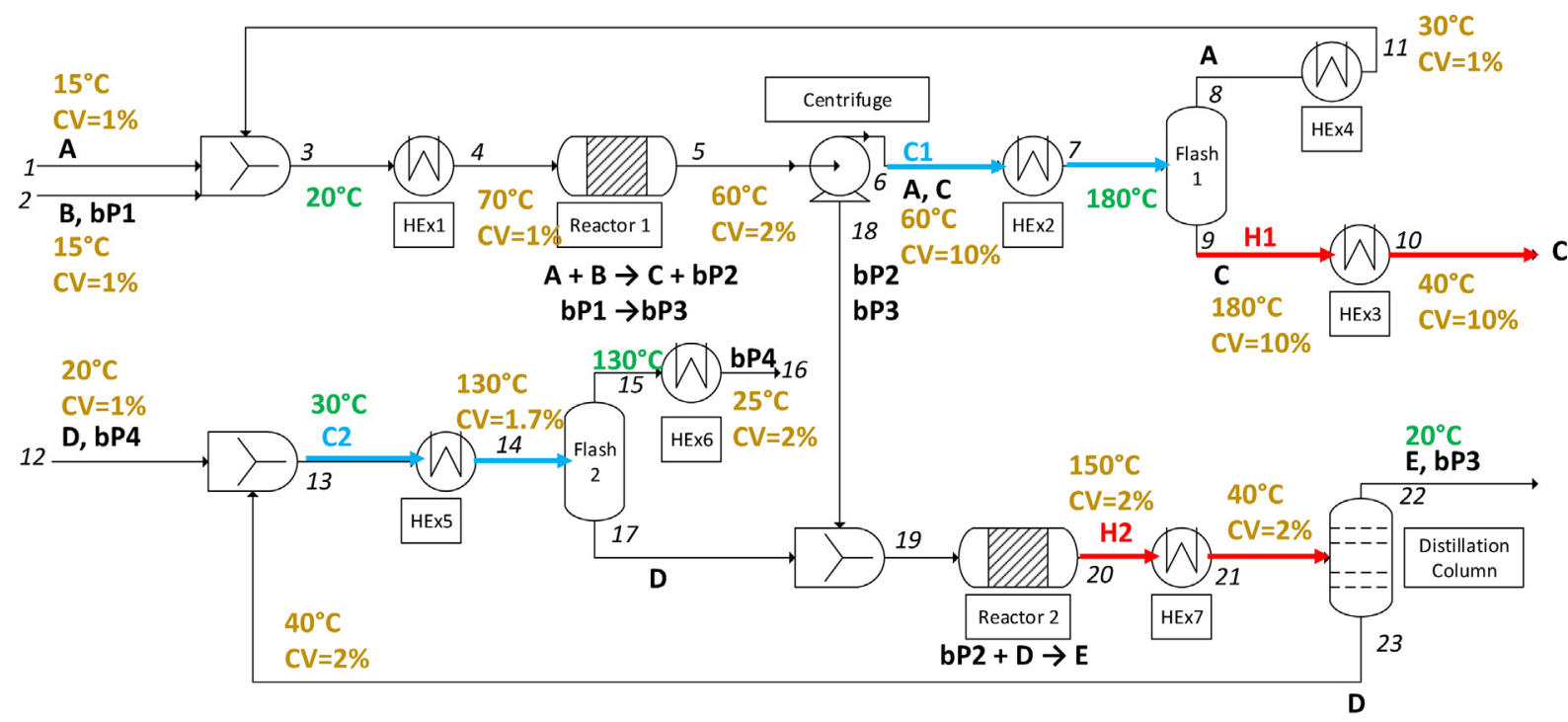

Measured data

Fig. 10 - Simple Process at the end of step 1. (For interpretation of the references to colour in the text, the reader is referred to the web version of this article.) 


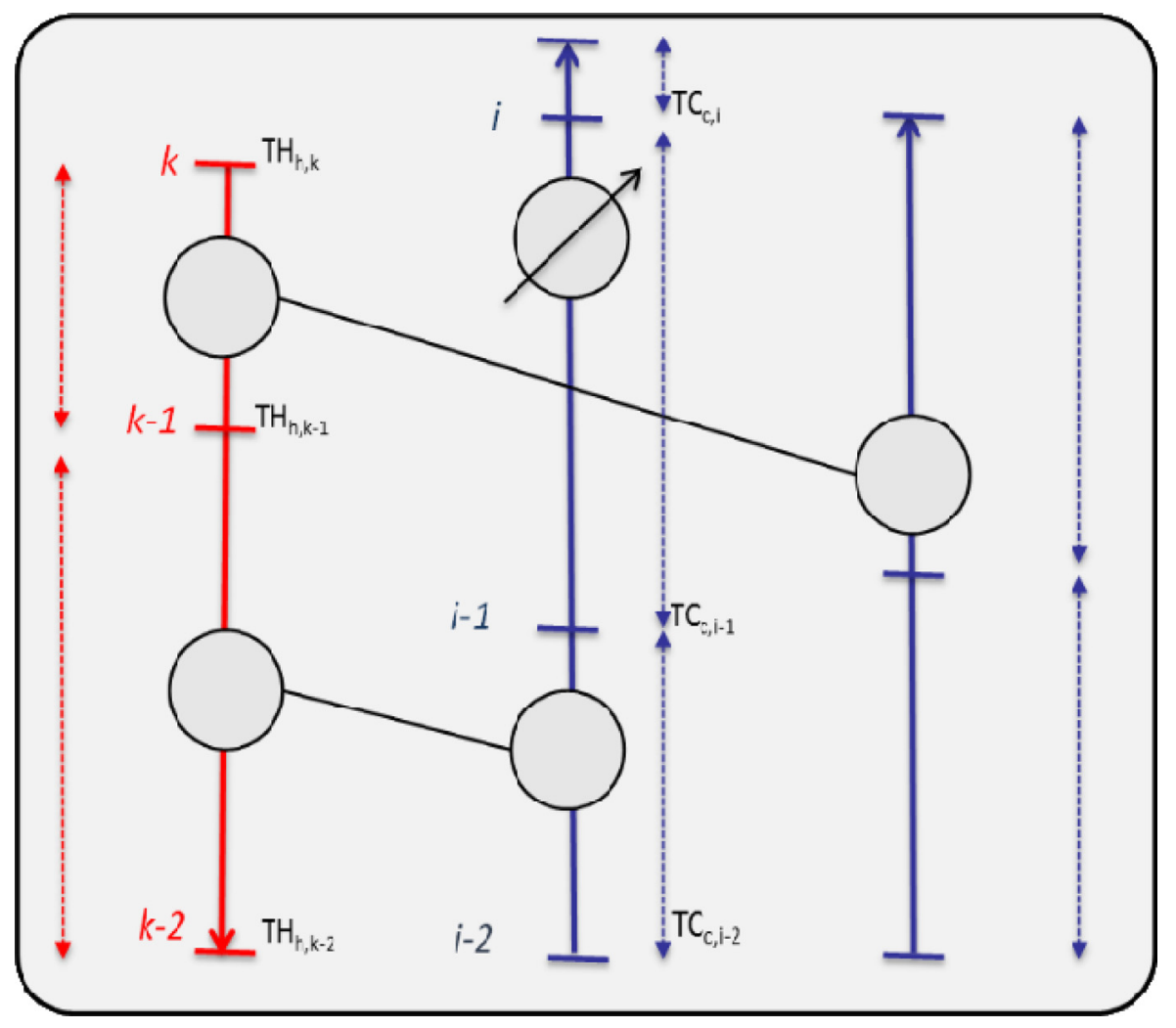

Fig. 11 - Notion of temperature interval.

$\left[\mathrm{TH}_{\mathrm{h}, \mathrm{k}}, \mathrm{TH}_{\mathrm{h}, \mathrm{k}-1}\right]$ and $\left[\mathrm{TH}_{\mathrm{h}, \mathrm{k}-1}, \mathrm{TH}_{\mathrm{h}, \mathrm{k}-2}\right]$. Nevertheless, the number of interval of each stream is a priori unknown, as well as the temperature defining the bounds of these intervals.

Thanks to such representation, the Heat Exchanger Network synthesis problem can be seen as a transshipment problem of energy from hot streams (on the left) toward cold streams (on the right). Formally, this classical problem can be modelled using a bipartite flow graph with potential considerations. The use of such a graphical and formal support allows a systematic and unambiguous construction of the MILP model. A vertex is associated to each stream of the problem. Parameters $N_{i}$ define the maximum number of exchanges desired for stream $i$. This parameter is set a priori in order to control the complexity of the HEN topology. Indeed, the resulting HEN will be a priori all the more integrated as the $N_{i}$ are high. As each stream $i$ can be divided into $N_{i}$ temperature intervals, each interval $j$ is also associated to a vertex, named respectively $\mathrm{HI}_{\mathrm{i}, \mathrm{j}}$ for hot stream and $\mathrm{CI}_{\mathrm{i}, \mathrm{j}}$ for cold stream. These vertices are annotated with a potential $T_{i, j}$ corresponding to the output temperature of the corresponding interval. The two subset of vertices $\mathrm{HI}_{\mathrm{i}, \mathrm{j}}$ and $\mathrm{CI}_{\mathrm{i}, \mathrm{j}}$ respectively form the two subsets $\mathrm{X} 1$ and $\mathrm{X} 2$ of a classical bipartite flow graph. Parameter Ndivi define the maximum number of division (or sub-streams) that an interval of a stream $i$ can be subject to. The mixing of the substreams of a stream $i$ is imposed to be isothermal. Thus, each interval of a stream $i$ can exchange heat with a utility or with Ndiv (at most) intervals of streams located on the other side.

Fig. 12 displays the bipartite flow graph for a system composed of 2 hot streams (H1 and H2) and 2 cold streams (C1 and C2), each stream participating in 4 exchanges at most. Vertices $\mathrm{H1}, \mathrm{H} 2, \mathrm{C} 1$ and $\mathrm{C} 2$ on the graph represent respectively each stream. As an example, the potential exchanges of the third interval of hot stream $1 \mathrm{HI}_{1,3}$ is drawn (yellow and brown arrows).
The bipartite flow problem then evolved into an assignment problem between two sets of vertexes, where the flows are the heat exchanged between an interval $k$ of a hot stream $h$ to an interval $i$ of a cold stream $c$ or to a cold utility (and vice versa). Thus, each interval $k$ of a hot stream $h$ has to be paired up with an interval $i$ of a cold stream $c$ or with a cold utility. The physical constraints are easily deduced from the graph. These are written on the basis of:

- Flow balance on each node of the graph.

- Capacity constraints of each arcs.

- Assignment constraints for the binary variables.

- Potential between intervals in order to take into account the $1^{\text {st }}$ and $2^{\text {nd }}$ principles of Thermodynamic.

The complete nomenclature and equations of the model are given in the Supplementary material in Appendix A at the end of the paper.

\subsection{Application on the Simple Process example}

For the SP example, several configurations can be built when modifying model parameters such as the maximum intervals count $N_{i}$ or the criterion formulation. For instance, Table 5 presents two configurations and the associated model parameters.

- Configuration 01 that achieves the MER with no constraints on the number of heat exchangers in Fig. 13.

- Configuration 02 that includes an additional constraint on the number of heat exchangers and consumes $40 \mathrm{~kW}$ more than the configuration 01 in Fig. 14.

The energy properties of both configurations are reported in Table 5. 


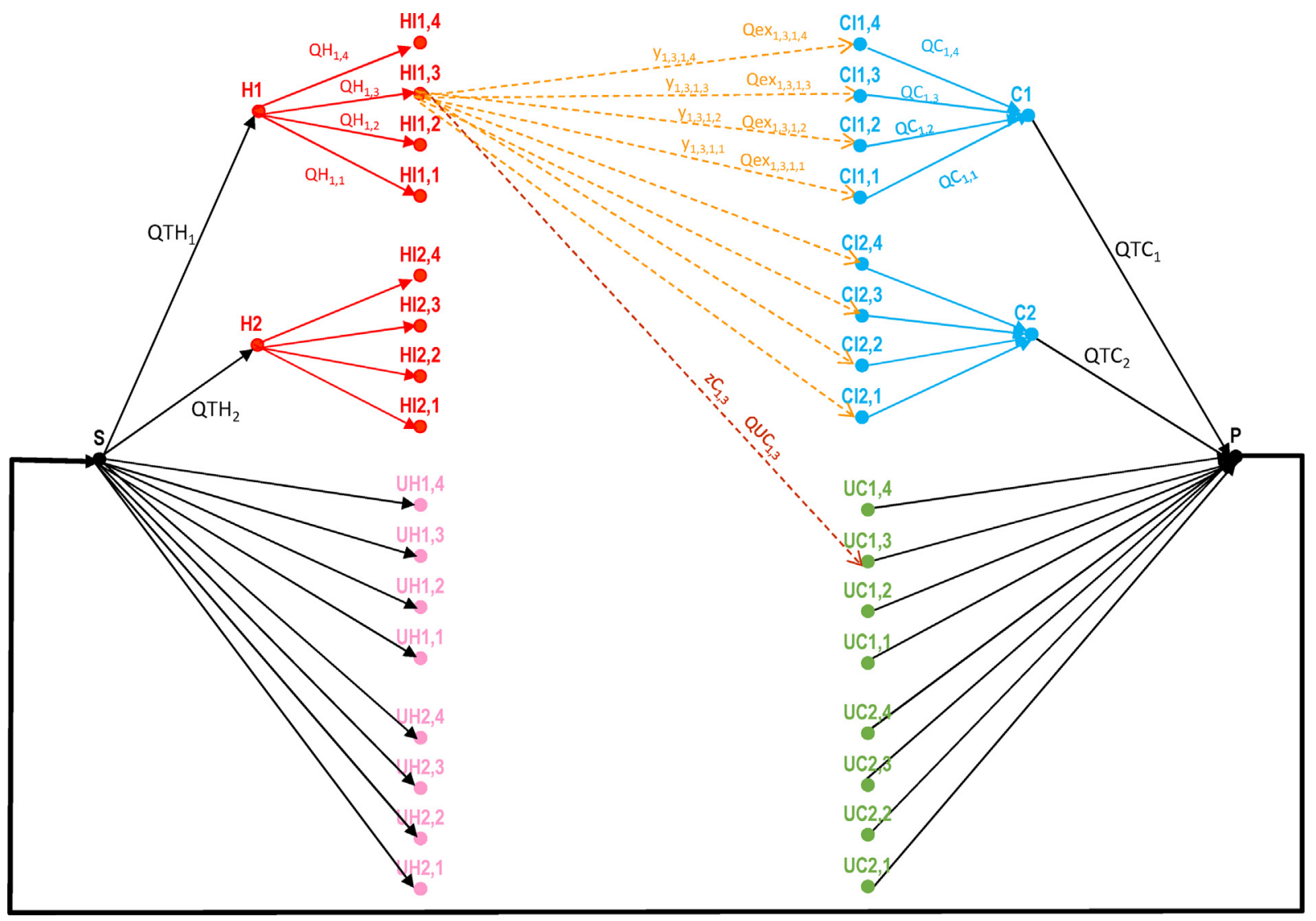

Fig. 12 - Bipartite flow graph of the illustrative example. (For interpretation of the references to colour in the text, the reader is referred to the web version of this article.)

\section{Table 5 - HEN configurations properties.}

\begin{tabular}{llllll} 
Configuration & QUC & QUH & Heat exchanger count & Model parameter Ndiv & Number of heat exchangers constraint \\
\hline 01 & $160 \mathrm{~kW}$ & $60 \mathrm{~kW}$ & 8 & 4 & 10 \\
02 & $200 \mathrm{~kW}$ & $100 \mathrm{~kW}$ & 5 & 4 & 5
\end{tabular}

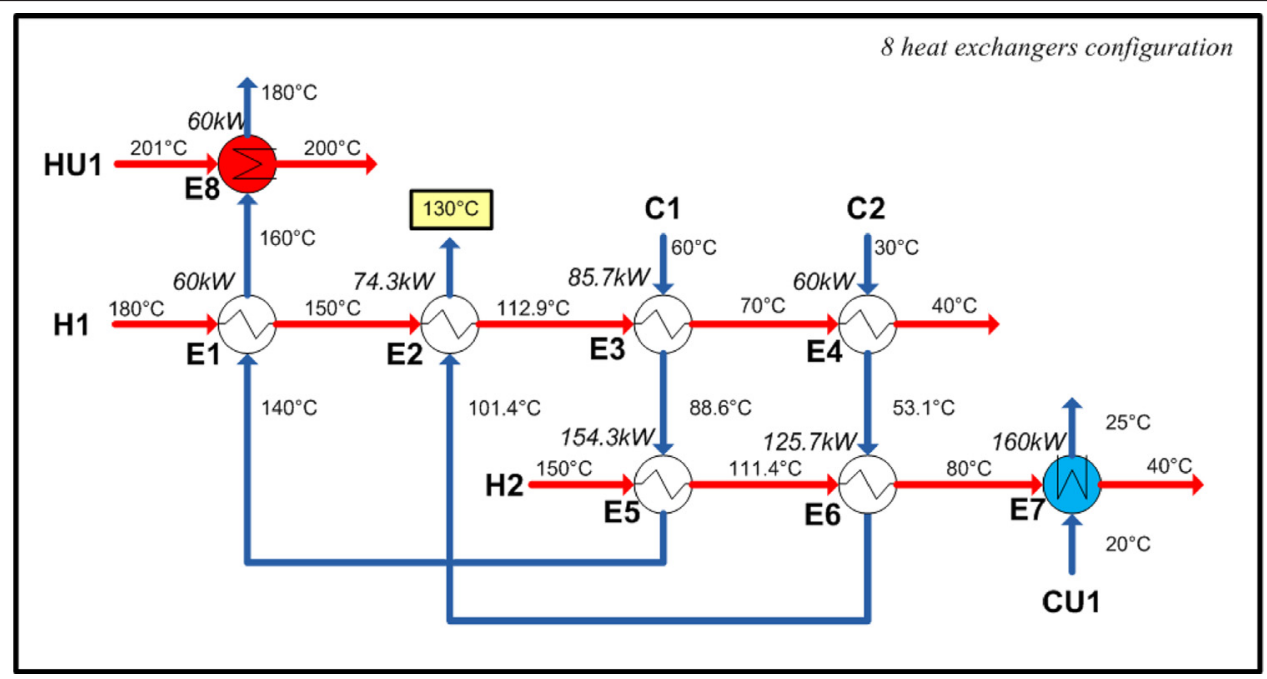

Fig. 13 - Configuration 01 (MER).

\section{Step 3: assessment of robustness} indicator

\subsection{HEN behaviour simulation}

The temperature of an inlet stream of a HEN is subject to variations following the normal distribution that was characterised as part of the previous steady-state regime. The simulation of the model response of a HEN is detailed in
Floquet et al. (2016). Eq. (1) shows the basic linear model used to evaluate the output temperatures of a hot stream $\mathrm{T}_{\text {out }}^{\mathrm{h}}$ and a cold stream $T_{\text {out }}^{c}$ based on the input temperatures $T_{\text {in }}^{h}$ and $T_{\text {in }}^{c}$ for a counter-current heat exchanger displayed in Fig. 15.

$$
\left(\begin{array}{c}
T_{\text {out }}^{h} \\
T_{\text {out }}^{c}
\end{array}\right)=\left(\begin{array}{cc}
K_{2} & 1-K_{2} \\
1-K_{1} & K_{1}
\end{array}\right)\left(\begin{array}{c}
T_{\text {in }}^{h} \\
T_{\text {in }}^{c}
\end{array}\right)
$$




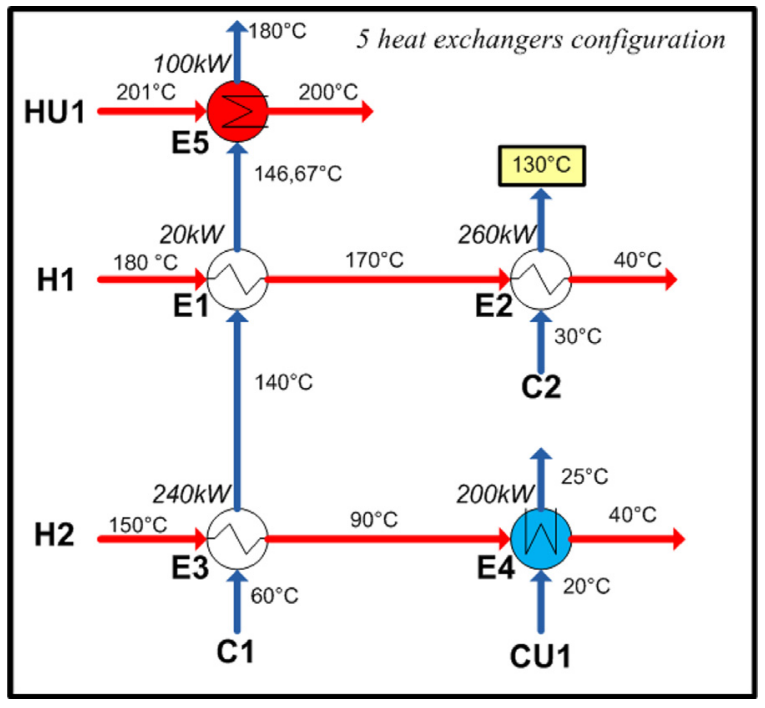

Fig. 14 - Configuration 02.

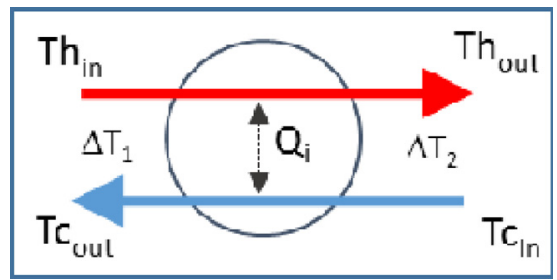

Fig. 15 - Counter-current heat exchanger.

where $K_{1}$ and $K_{2}$ depend only on heat exchanger characteristics (U, A, $F_{h}, C p_{h}, F_{C}, C p_{c}$ ) as shown in Eqs. (2) and (3):

$K_{1}=\left[\frac{\left(F_{c} C p_{c}-F_{h} C p_{h}\right) e^{U A\left(\frac{1}{F_{h} C p_{h}}-\frac{1}{F_{c} C p_{c}}\right)}}{F_{c} C p_{c} e^{U A\left(\frac{1}{F_{h} C p_{h}}-\frac{1}{F_{c} C p_{c}}\right)}-F_{h} C p_{h}}\right]$

$K_{2}=\left[\frac{F_{c} C p_{c}-F_{h} C p_{h}}{F_{c} C p_{c} e^{U A\left(\frac{1}{F_{h} C p_{h}}-\frac{1}{F_{c} C p_{c}}\right)}-F_{h} C p_{h}}\right]$

Calculation of the output temperatures of a whole HEN is based on solving the linear system $A T=b$ as shown in Eq. (4), where:

$A:\left(\begin{array}{ccccccccc}1 & 0 & 0 & 0 & \ldots & 0 & 0 & 0 & 0 \\ 0 & 1 & 0 & 0 & \ldots & 0 & 0 & 0 & 0 \\ -K_{2}^{E_{1}} & K_{2}^{E_{1}}-1 & 1 & 0 & \ldots & 0 & 0 & 0 & 0 \\ K_{1}^{E_{1}}-1 & -K_{1}^{E_{1}} & 0 & 1 & \ldots & 0 & 0 & 0 & 0 \\ \ldots & \ldots & \ldots & \ldots & \ldots & \ldots & \ldots & \ldots & \ldots \\ 0 & 0 & -1 & 0 & \ldots & 1 & 0 & 0 & 0 \\ 0 & 0 & 0 & 0 & \ldots & 0 & 1 & 0 & 0 \\ 0 & 0 & 0 & 0 & \ldots & -K_{2}^{E_{4}} & K_{2}^{E_{4}}-1 & 1 & 0 \\ 0 & 0 & 0 & 0 & \ldots & K_{1}^{E_{4}}-1 & -K_{1}^{E_{4}} & 0 & 1\end{array}\right) \times T:\left(\begin{array}{c}T_{\text {in, }, E_{1}}^{h} \\ T_{\text {in, }}^{c} \\ T_{\text {out }, E_{1}}^{h} \\ T_{\text {out }, E_{1}}^{c} \\ \ldots \\ T_{\text {in, }, E_{4}}^{h} \\ T_{\text {in, }, E_{4}}^{c} \\ T_{\text {out }, E_{4}}^{h} \\ T_{\text {out }, E_{4}}^{c}\end{array}\right)=b:\left(\begin{array}{c}T_{\text {in }}^{H 2} \\ 0 \\ 0 \\ 0 \\ \ldots \\ 0 \\ T_{\text {in }}^{C 1} \\ 0 \\ 0 \\ 0\end{array}\right)$

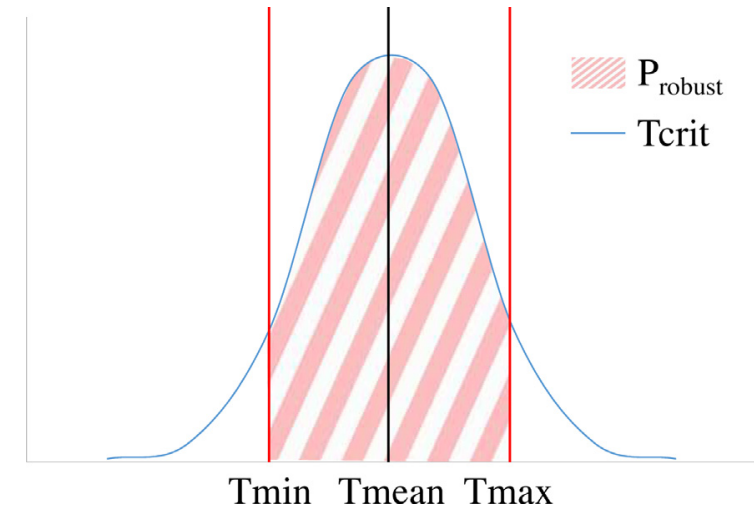

Fig. 16 - Robustness indicator $P_{\text {robust }}$.

Table 6 - Results of robustness study for the SP.

\begin{tabular}{lll} 
& \multicolumn{2}{c}{ Probust } \\
\cline { 2 - 3 } Input variabilities & Config 01 (MER) & Config 02 \\
\hline H1 + C1 & 0.960 & 0.499 \\
\hline
\end{tabular}

- $\mathrm{A}$ is the matrix gathering all the equations about each heat exchangers of the network and the connections between the exchangers as shown in Eq. (4).

The linearity of the problem for a given HEN ensures that the response to normally distributed input temperatures will also be normally distributed, as long as the input temperatures are independent. The mean response of the system is obtained from the resolution of $A \cdot T_{\text {mean }}=b_{\text {mean }}$. The variance of the response can also be calculated linearly by propagating the variance of each individual element. Only the system input temperatures are varied in this study.

\subsection{Evaluation of the HEN robustness}

The analysis of the HEN's response to variations in input temperatures yields the definition of a robustness indicator, which is used to compare several HEN designs for a given process. The robustness indicator is defined as the probability for the critical stream output temperature to stay within its tolerance limits [Tmin; Tmax], as shown in Fig. 16. The indicator is equal to 1 if $99.7 \%$ of the distribution $(3 \sigma)$ is within the boundaries.

- $T$ is a vector composed of all the temperatures of the system. A system with $n$ heat exchangers is displayed as an example in Eq. (4).

- The vector $b$ includes all the known input temperatures of the system. 


\section{Table 7 - Input variable temperature.}

Variable stream

$$
\mathrm{T}_{\text {mean }}
$$

$\sigma_{\mathrm{T}}$

Application on the Simple Process example

The two HEN configuration responses to the variabilities of $\mathrm{H} 1$ and $\mathrm{C} 1$ were evaluated. The robustness was calculated with C2 as the critical stream and the results are displayed in Table 6.

After this study, the conclusion is that configuration 01 is more robust towards the identified variabilities and in regard of the selected critical stream. For the HEN 01, that reaches the MER, to be more robust is a rather unexpected result as it is more integrated. This confirms that it is essential to carry out this thorough data analysis to establish a robustness criterion.

\section{Industrial case study}

This methodology was applied on an industrial site of Vinyl Chloride Monomer (VCM) production. VCM production process is a complex process with an intricate structure due to several reactors and separation sections. Hence the robustness issue is vital to provide an efficient HEN for the process.

The VCM plant was studied in order to analyze and reduce its energy consumption. This process already has a few integrated heat exchangers. The first objective of the study is to establish an energy diagnosis to evaluate the current solution. Then calculate the robustness criterion over each HEN. Two networks are compared on this level.

\subsection{Statistical analysis and steady state detection}

From all the 198 sensors analysed with EDiFy, 165 sensors are part of the representative data set as they are all in steadystate regime over the same period. The whole process was modelled in ProSimPlus ${ }^{\odot}$ (422 streams). The process model was validated with a maximum relative difference of $10 \%$ between redundant information on temperature, flowrates or pressure and the simulation values. Concerning the variations, the process is globally very stable ( 118 sensors under $2 \%$ of coefficient of variation). Many critical streams were identified as the process is well optimized. The energy diagnosis revealed that the hot utility usage can be reduced to $0 \mathrm{~kW}$ with a MER network configuration. Several scenarii will be established and analysed in terms of robustness in order to find a suitable HEN handling on-site constraints. Concerning the robustness analysis, two HEN are here-by presented.

\subsection{HEN behaviour simulation}

Two configurations were studied. The HEN were designed according to two scenarii:

- Scenario 1: all the process hot and cold streams were considered for the HEN design.

- Scenario 2: the already integrated streams were put aside to only reconsider streams relying on utilities.

One variation impacting critical streams is studied in particular. In both configurations, other variations were either coupled with utilities or not impacting critical streams. The
Table 8 - Critical streams output temperature bounds.

\begin{tabular}{llll} 
Critical streams & $\mathrm{T}_{\min }$ & $\mathrm{T}_{\text {mean }}$ & $\mathrm{T}_{\max }$ \\
\hline $\mathrm{A} 23$ & $165.20^{\circ} \mathrm{C}$ & $167.00^{\circ} \mathrm{C}$ & $168.80^{\circ} \mathrm{C}$ \\
$\mathrm{A} 17$ & $217.35^{\circ} \mathrm{C}$ & $218.00^{\circ} \mathrm{C}$ & $218.65^{\circ} \mathrm{C}$ \\
\hline
\end{tabular}

\section{Scenario 01}

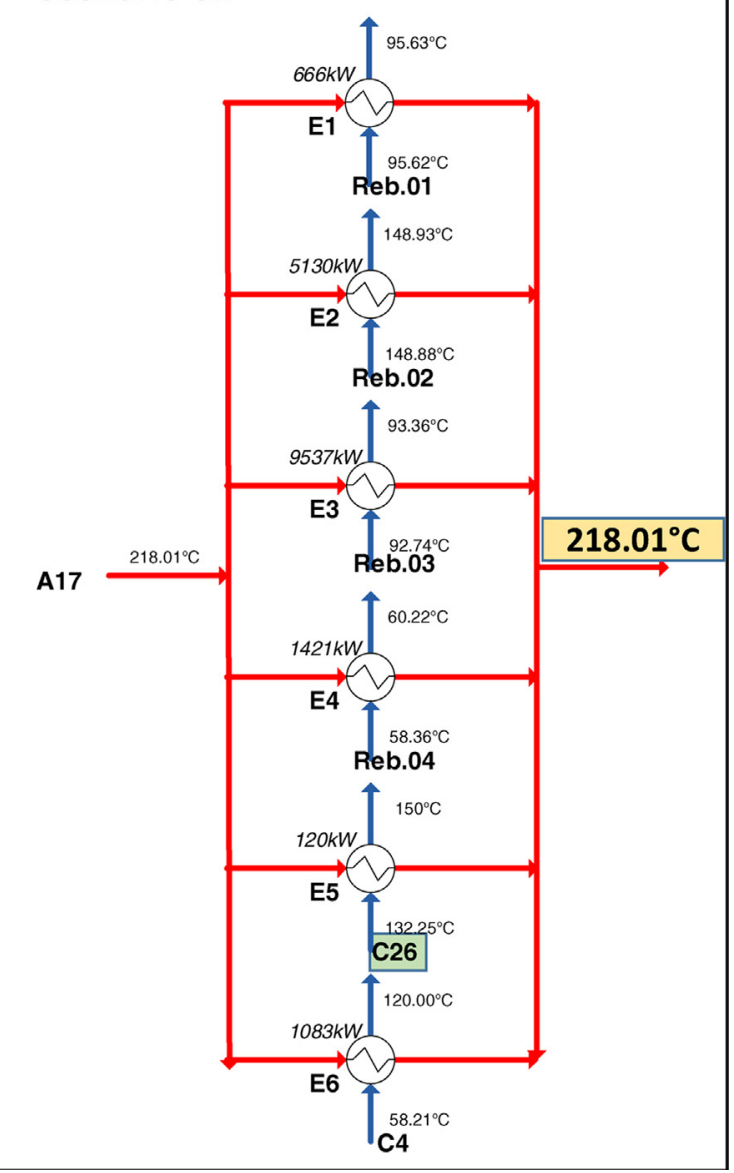

Fig. 17 - Partial HEN Scenario 01.

\section{Table 9 - Robustness indicator results.}

\begin{tabular}{lll} 
& \multicolumn{2}{c}{$\mathrm{P}_{\text {robust }}$} \\
\cline { 2 - 3 } Input variabilities & Config 01 & Config 02 \\
\hline C26 & 1.0 & 0.73 \\
\hline
\end{tabular}

stream variation properties are displayed in Table 7. The critical streams properties are displayed in Table 8.

The two parts of the HEN impacted by the disturbance are displayed in Figs. 17 and 18. Configuration 01 actually proposes a coupling different from what is already done on the actual process. Configuration 02 couples up the remaining streams. A17 (hot stream displayed in Fig. 17) which is part of an existing integration on the site has been left out of the study for configuration 02 .

\subsection{Robustness assessment}

The robustness indicator was calculated upon each configuration and displayed in Table 9. The results show that by reconsidering the existing solution, a new coupling was highlighted (A17-C26) which is more robust than a HEN with only the non-integrated streams. 


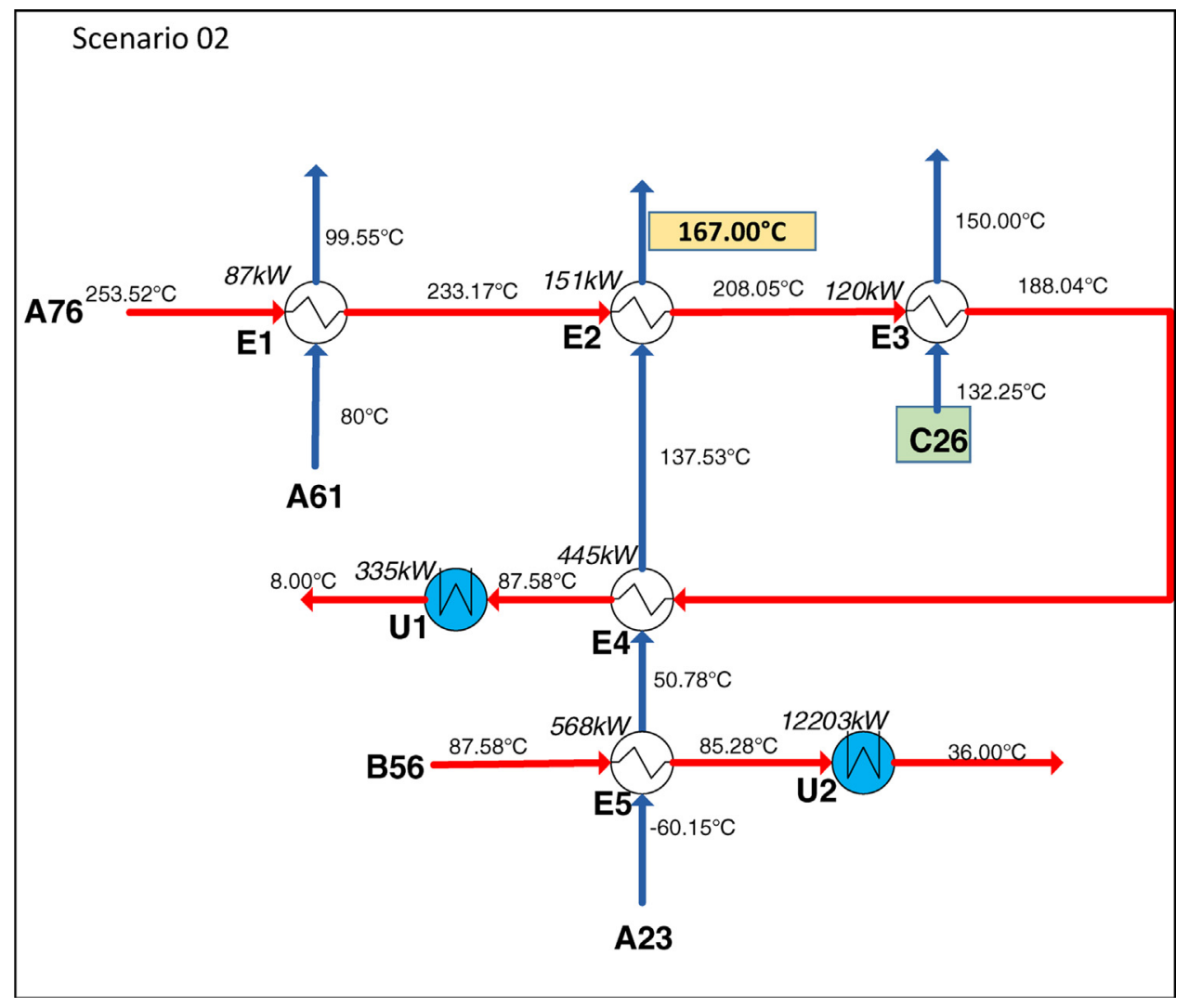

Fig. 18 - Partial HEN Scenario 02.

\section{Conclusion}

Over the last decades, Heat Exchanger Network design topic has been the subject of many studies leading to the development of several methodologies and software. Yet, from an engineer point of view, this task still remains a very arduous one because recovery solutions proposed by this method do not take all the constraints imposed by the site into account. To address this issue, RREFlex project proposes an original approach which consists in an iterative process relying on:

- An enhanced data collection to precisely identify the site constraints and specificities.

- The proposal and evaluation of several HEN configurations achieved by an optimization approach based on Mixed Integer Linear Programming (MILP) that minimizes energy consumption.

- The post-evaluation of the performances of these configurations with KPI relative to on-site considerations such as topology of the HEN or its flexibility in addition to more traditional indicators like energy consumption and global costs.

- A retroaction loop to take into account new constraints formulated by the engineer and the synthesis of new HEN to finally obtain configurations that will perfectly fulfill all the process constraints.

Among these constraints, robustness appears as one of the most crucial ones. In this article, the first level of flexibility has been addressed. It concerns the ability of the system to absorb disturbances ("noises" with low amplitude) without changing the flow rates of utilities. To enable RREFlex software to assess the robustness of a given HEN, a three-step methodology has been developed starting from an enhanced data collection for the calculation of enriched data for pinch key values (mean values and standard deviation of temperatures and coefficient of variation) and ending with the definition of a robustness criterion.

This methodology has then been successfully applied to an industrial case study. In the future, the robustness will be used as an optimization criterion in the model dedicated to the synthesis of HEN in order to obtain straightaway robust configurations. Moreover, other levels of robustness such as resilience, adaptability and management of intermittency will be addressed.

\section{Acknowledgements}

This work is part of the RREFlex project whose general goal is the development of software dedicated to the synthesis of flexible Heat Exchanger Networks (HEN). The LGC greatly acknowledge TOTAL and the ADEME (French Environment and Energy Management Agency) for the financial support of this project.

\section{Appendix A. Supplementary data}

Supplementary data associated with this article can be found, in the online version, at https://doi.org/10.1016/j.cherd.2017.11.036.

\section{References}

Barbaro, A., Bagajewicz, M.J., 2005. New rigorous one-step MILP formulation for heat exchanger network synthesis. Comput. Chem. Eng. 29 (9), 1945-1976.

Björk, K.-M., Westerlund, T., 2002. Global optimization of heat exchanger network synthesis problems with and without the 
isothermal mixing assumption. Comput. Chem. Eng. 26 (11), 1581-1593.

Chen, L.C., Hung, P.S., 2004. Simultaneous synthesis of flexible heat exchange networks with uncertain source-stream temperatures and flow rates. Ind. Eng. Chem. Res. 43, 4451-4462.

Escobar, M., Trierweiler, J.O., 2013. Optimal heat exchanger network synthesis: a case study comparison. Appl. Therm. Eng. 51 (1-2), 801-826.

Escobar, M., Trierweiler, J.O., Grossmann, I.E., 2013. Simultaneous synthesis of heat exchanger networks with operability considerations: flexibility and controllability. Comput. Chem. Eng. 55, 158-180.

Floquet, P., Hétreux, G., Hétreux, R., Payet, L., 2016. Analysis of operational heat exchanger network robustness via Interval Arithmetic. Comput. Aided Chem. Eng. 38, 1401-1406.

Fukunaga, K. (Ed.), 1990. Introduction to Statistical Pattern Recognition., Second Edition. Academic Press, Boston, pp. ii.

Furman, K.C., Sahinidis, N.V., 2002. A critical review and annotated bibliography for heat exchanger network synthesis in the 20th century. Ind. Eng. Chem. Res. 41 (10), 2335-2370.

Gundersen, T., Naess, L., 1990. The synthesis of cost optimal heat exchanger networks. Heat Recovery Syst. CHP 10 (4), 301-328.

Isafiade, A.J., Fraser, D.M., 2008. Interval-based MINLP superstructure synthesis of heat exchange networks. Chem. Eng. Res. Des. 86 (3), 245-257.

Kourti, T., MacGregor, J.F., 1995. Process analysis, monitoring and diagnosis, using multivariate projection methods. Chemometr. Intell. Lab. Syst. 28 (1), 3-21.

Kresta, J.V., Macgregor, J.F., et al., 1991. Multivariate statistical monitoring of process operating performance. Can. J. Chem. Eng. 69 (1), 35-47.

Linnhoff, B., Hindmarsh, E., 1983. The pinch design method for heat exchanger networks. Chem. Eng. Sci. 38 (5), 745-763.

Masoud, I.T., Abdel-Jabbar, N., et al., 2016. Methodological framework for economical and controllable design of heat exchanger networks: steady-state analysis, dynamic simulation, and optimization. Appl. Therm. Eng. 104, 439-449.

Mehta, R.K.C., Devalkar, S.K., et al., 2001. An optimization approach for evolutionary synthesis of heat exchanger networks. Chem. Eng. Res. Des. 79 (2), 143-150.

Mikkelsen, J., Qvale, B., 2001. A combinatorial method for the automatic generation of multiple, near-optimal heat exchanger networks. Chem. Eng. Res. Des. 79 (6), 663-672.

Morar, M., Agachi, P.S., 2010. Review: important contributions in development and improvement of the heat integration techniques. Comput. Chem. Eng. 34 (8), 1171-1179.

Pereira, P.M., Fernandes, M.C., et al., 2017. FI2EPI: a heat management tool for process integration. Appl. Therm. Eng. 114, 523-536.

Pintarič, Z.N., Kravanja, Z., 2004. A strategy for MINLP synthesis of flexible and operable processes. Comput. Chem. Eng. 28 (6-7), 1105-1119.

Romagnoli, J.A., Sanchez, M.C., 1999. Data Processing and Reconciliation for Chemical Process Operations. Academic Press.

Saboo, A.K., Morari, M., et al., 1985. Design of resilient processing plants-VIII. A resilience index for heat exchanger networks. Chem. Eng. Sci. 40 (8), 1553-1565.

Smith, R., Jobson, M., et al., 2010. Recent development in the retrofit of heat exchanger networks. Appl. Therm. Eng. 30 (16) 2281-2289.

Sreepathi, B.K., Rangaiah, G.P., 2014. Review of heat exchanger network retrofitting methodologies and their applications. Ind. Eng. Chem. Res. 53 (28), 11205-11220.

Swaney, R.E., Grossmann, I.E., 1985. An index for operational flexibility in chemical process design. Part I: formulation and theory. AIChE J. 31 (4), 621-630.

Venkatasubramanian, V., Rengaswamy, R., et al., 2003. A review of process fault detection and diagnosis. Comput. Chem. Eng. 27 (3), 327-346.

Verheyen, W., Zhang, N., 2006. Design of flexible heat exchanger network for multi-period operation. Chem. Eng. Sci. 61, 7730-7753.

Yee, T.F., Grossmann, I.E., et al., 1990. Simultaneous optimization models for heat integration-I. Area and energy targeting and modeling of multi-stream exchangers. Comput. Chem. Eng. 14 (10), 1151-1164.

Yee, T.F., Grossmann, I.E., 1990. Simultaneous optimization models for heat integration-II. Heat exchanger network synthesis. Comput. Chem. Eng. 14 (10), 1165-1184. 